\title{
Mechanism of the Ferrocyanide-Iodate-Sulfite Oscillatory Chemical Reaction
}

\author{
Viktor Horváth, Irving R. Epstein* and Kenneth Kustin ${ }^{\mathrm{a}}$ \\ Department of Chemistry, Brandeis University, Waltham, MA 02454-9110, USA
}

\section{Supporting Information (SI)}

SI consists of the detailed description of the determination of sulfite ions: (1) background in literature, (2) method optimization, (3) assessment of the effect of interfering ions present in the FIS reaction mixture.

\section{Determination of $\left[\mathrm{SO}_{3}{ }^{2-}\right]$ in a reaction mixture of the oscillatory FIS reaction}

\section{(1) Literature method}

We sought a simple analytical method that is suitable to determine the total sulfite concentration in the oscillatory mixture of the FIS reaction. The reaction mixture may contain unreacted reactants as well as reactive intermediates such as $\mathrm{I}^{-}$and $\mathrm{Fe}(\mathrm{CN})_{6}{ }^{3-}$. We aimed to avoid sample treatment and separation; therefore quenching the FIS/Landolt reaction is necessary. We found a potentially suitable chemical reaction: dye formation between sulfite, ammonia, and o-diphtalaldehyde (OPA) at $\mathrm{pH}>8$, reported by Zhang et $a l^{20}$. The product and the kinetics of this reaction have not been characterized. Based on this reaction, Abdel-Latif ${ }^{21}$ developed a method for determining sulfite in food samples. He reported that sulfite concentrations in the range of 5-100 $\mu \mathrm{M}$ can be determined using this calibration technique. This reaction seemed to be ideal for our purpose, as models predicted the peak concentration of total sulfite in the reaction mixture to be on the order of $10 \mathrm{mM}$. Thus, small sample aliquots could be used, allowing for taking multiple measurements within a single cycle of the FIS reaction without disturbing the

\footnotetext{
a Emeritus
} 
oscillatory dynamics. Due to the high $\mathrm{pH}$ that the dye formation needs and due to the high dilution, any reaction between sulfite and iodate is quenched without additional reactants. However, we needed to assess the potential interference due to the presence of reactants and intermediates.

\section{(2) Method optimization}

Our initial attempts to reproduce the results reported by Abdel-Latif were unsuccessful. Their method needed optimization. We found the reported ammonia concentration to be much too high, and the peak wavelength of the dye was different $(480 \mathrm{~nm})$. The reactant order, the $\mathrm{pH}$ of the color development and the reaction time needed to be optimized for measuring sulfite concentrations at room temperature.

We used the following protocol has been used for obtaining a calibration curve for standards. $20 \mathrm{mM}$ OPA solution buffered at $\mathrm{pH}=7$ using a phosphate buffer $\left(\left[\mathrm{PO}_{4}{ }^{3-}\right]_{\text {tot }}=70 \mathrm{mM}\right), 240 \mathrm{mM}$ disodium hydrogen phosphate solution, $1 \mathrm{~N} \mathrm{NaOH}$ solution, and distilled water were pipetted into a glass vial in this order. Aliquots of sodium sulfite solution were then added to the vials and the contents were mixed. Finally, $90 \mathrm{mM}$ ammonia solution was pipetted, and the vials were capped and mixed once again. The resulting reactant concentrations were as follows: $[\mathrm{OPA}]=10 \mathrm{mM},\left[\mathrm{HPO}_{4}{ }^{2-}\right]=75 \mathrm{mM},\left[\mathrm{NH}_{4} \mathrm{OH}\right]=1.5 \mathrm{mM}$. The $\mathrm{pH}$ of the reactant mixture was measured to be around 11 . At this $\mathrm{pH}$ the reaction gradually produces a purple dye with $\lambda_{\max }=550 \mathrm{~nm}$. 


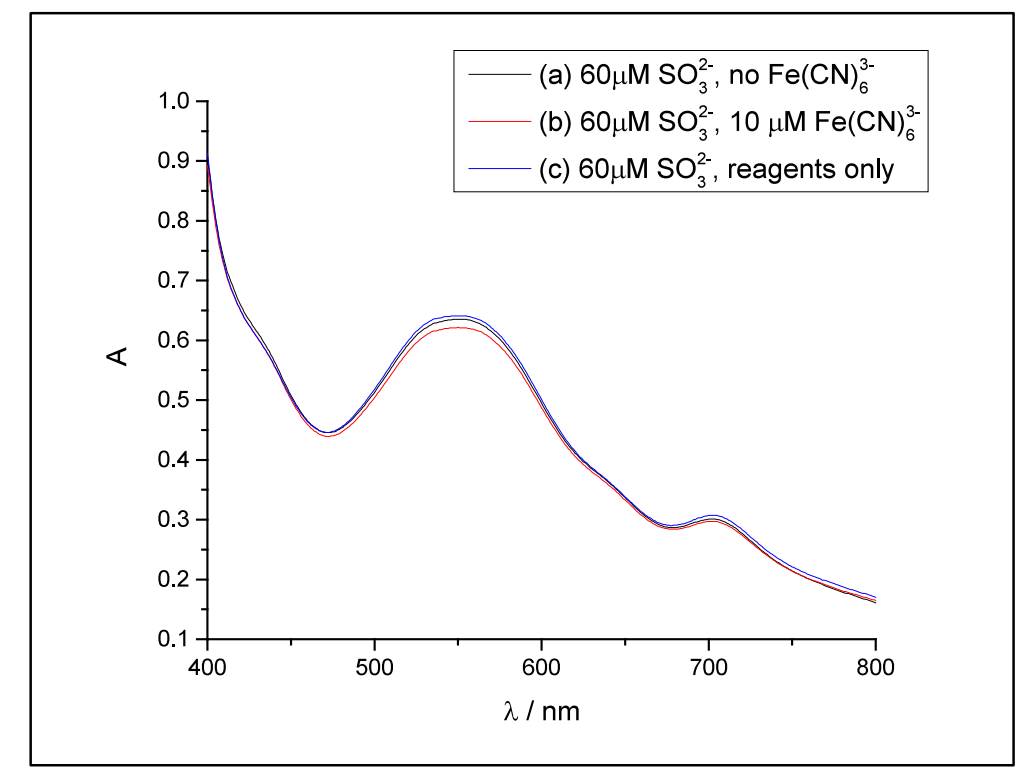

Figure S1.: Visible spectra of dye with and without interfering ions. Concentrations for $(a)$, (b), (c): [OPA] $=10 \mathrm{mM},\left[\mathrm{HPO}_{4}{ }^{2-}\right]=75 \mathrm{mM},\left[\mathrm{NH}_{3}\right]=1.5 \mathrm{mM},\left[\mathrm{SO}_{3}{ }^{2-}\right]=60 \mu \mathrm{M}, \mathrm{pH}=11$, reaction time 33 min at $22^{\circ} \mathrm{C}$. (b) $\left[\mathrm{IO}_{3}{ }^{-}\right]=510 \mu \mathrm{M},\left[\mathrm{I}^{-}\right]=200 \mu \mathrm{M},\left[\mathrm{Fe}(\mathrm{CN})_{6}{ }^{4-}\right]=200 \mu \mathrm{M}$, (c) contains $\left[\mathrm{Fe}(\mathrm{CN})_{6}{ }^{3-}\right]=10 \mu \mathrm{M}$ in addition to the reactants of $(a)$

After approximately $33 \mathrm{~min}$ of development time, the spectra of the standards were taken against a blank that was prepared identically but without sulfite. Absorbance values at $550 \mathrm{~nm}$ were read and a calibration curve was produced (Figure S2). 


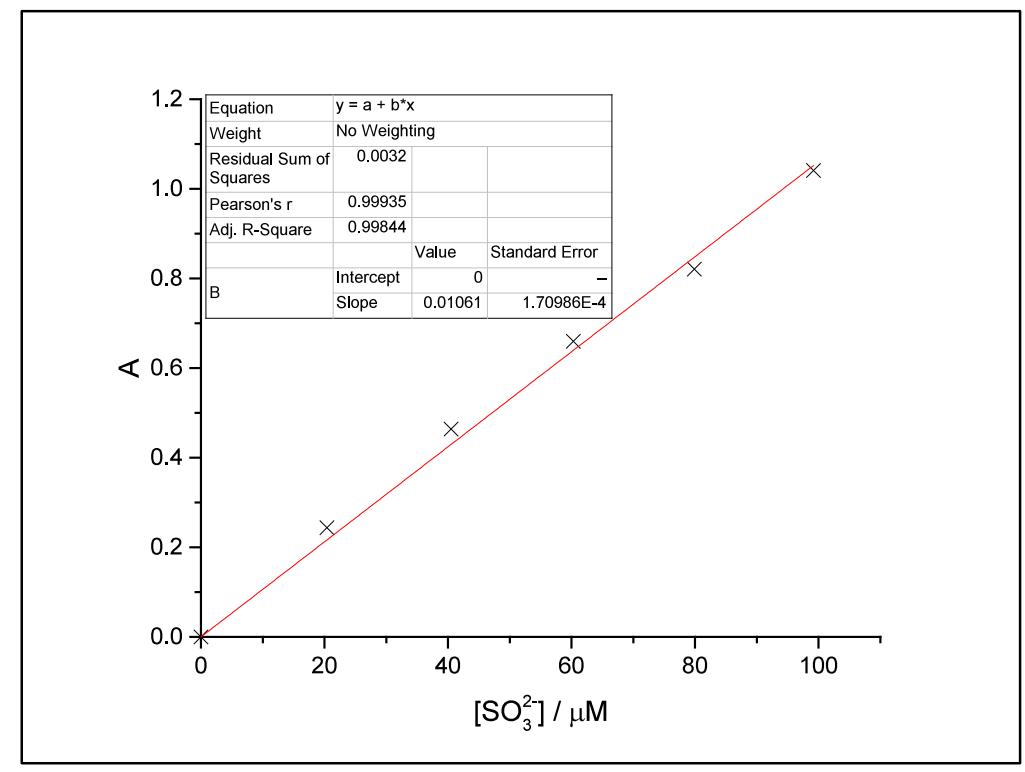

Figure S2. Calibration of $\left[\mathrm{SO}_{3}{ }^{2-}\right]_{T}$ determination in an oscillatory reaction mixture of the FIS reaction.

The fit is acceptable; however verification of the aliquot volumes as well as the reaction rate dependence on the exact reactant concentrations could further improve the fit.

\section{(3) Effects of interfering ions}

Given that the color development is not instantaneous, there was a high chance that the reactants and intermediates of the FIS reaction or the combination of them would interfere with the dye formation. Therefore, we determined if the reactants and some intermediates $\left(\mathrm{I}^{-}\right.$and $\left.\mathrm{Fe}(\mathrm{CN})_{6}{ }^{3-}\right)$ individually or jointly would interfere with the production of the dye. To test this, the procedure reported above was followed, but the reactant combinations listed in Table S1 were used as well as a sulfite concentration of $60 \mu \mathrm{M}$.

\begin{tabular}{|c|c|c|c|c|c|}
\hline Name & $\mathrm{KIO}_{3}$ & KI & $\mathrm{K}_{4} \mathrm{Fe}(\mathrm{CN})_{6}$ & $\mathrm{~K}_{3} \mathrm{Fe}(\mathrm{CN})_{6}$ & {$\left[\mathrm{Na}_{2} \mathrm{SO}_{3}\right]$} \\
\hline \multicolumn{6}{|l|}{ Blank } \\
\hline Test 1 & $510 \mu \mathrm{M}$ & & & & \\
\hline Test 2 & & $200 \mu \mathrm{M}$ & & & \\
\hline Test 3 & & & $200 \mu \mathrm{M}$ & & \\
\hline Test 4 & & & & $10 \mu \mathrm{M}$ & \\
\hline Test 5 & $510 \mu \mathrm{M}$ & $200 \mu \mathrm{M}$ & $200 \mu \mathrm{M}$ & $10 \mu \mathrm{M}$ & $60 \mu \mathrm{M}$ \\
\hline Test 6 & $510 \mu \mathrm{M}$ & & $200 \mu \mathrm{M}$ & & $60 \mu \mathrm{M}$ \\
\hline Reference & & & & & $60 \mu \mathrm{M}$ \\
\hline
\end{tabular}


Table S1. Reactant combinations for testing the interference of reactants and that of intermediates of the oscillatory FIS reaction.

Concentrations were chosen to exceed $\left(\mathrm{IO}_{3}{ }^{-}, \mathrm{Fe}(\mathrm{CN})_{6}{ }^{4-}, \mathrm{I}^{-}\right)$or to match $\left(\mathrm{Fe}(\mathrm{CN})_{6}{ }^{3-}\right)$ those that occur in the oscillatory FIS reaction The Blank and Tests 1 through 3 were indistinguishable, indicating that no color development occurs due to the presence of reactants or iodide ions. The spectrum of Test 4 was nearly baseline, although it contained the yellow ferricyanide initially. This result suggests that it reacted with the reactants of the dye formation reaction. By comparing the reference spectra and those of Test 5 and Test 6, shown as (a), (b), (c) respectively in Figure S2, a very slight difference can be seen. The values at $\lambda_{\max }: 0.635,0.622,0.641$ are very close to each other, suggesting that ferricyanide may cause a minor interference when it is at its peak concentration due to its reaction with sulfite (M17 - M20).

To assess whether this interference is insignificant at lower concentrations of sulfite, we measured the absorbance of solutions containing $20 \mu \mathrm{M}$ sulfite as well as $0,5,10,15,20 \mu \mathrm{M}$ ferricyanide. The absorbances at $\lambda_{\max }$ were $0.235,0.241,0.249,0.224,0.221$, showing that even though ferricyanide does interfere with the dye formation when its concentration exceeds that of sulfite ions, the error is less than $10 \%$ at the highest concentration of ferrocyanide.

Our primary goal was to determine the peak value of $\left[\mathrm{SO}_{3}{ }^{2-}\right]_{T}$, which potentially coincides with the minimum of $\left[\mathrm{Fe}(\mathrm{CN})_{6}{ }^{3-}\right]$. Therefore we accepted this method. The results that this method yields may have a small uncertainty at times when sulfite and ferricyanide ions are present simultaneously.

(20) Genfa, Z.; Dasgupta, P. K., Fluorometric Measurement of Aqueous Ammonium Ion in a FlowInjection System. Anal. Chem. 1989, 61, 408-412.

(21) Abdel-Latif, M. S., New Spectrophotometric Method for Sulfite Determination. Anal. Lett. 1994, $27,2601-2614$. 